\title{
English Medium Instruction in China's higher education: teachers' perspectives of competencies, certification and professional development
}

\author{
Ernesto Macaro (1), Shuangmiao Han (2)
}

(1) Department of Education, University of Oxford, Oxford, OX2 6PY, UK, ernesto.macaro@education.ox.ac.uk; (2) College of Education, Zhejiang University, Hangzhou,310028,China, shuangmiao.han@zju.edu.cn

Corresponding author: Shuangmiao Han (shuangmiao.han@zju.edu.cn, ORCiDs: 0000-00029174-2792)

This work was supported by the University of Oxford John Fell Research Fund under Grant [0003998]. 


\title{
English Medium Instruction in China's higher education: teachers' perspectives of competencies, certification and professional development
}

\begin{abstract}
Despite the increasing popularity of English Medium Instruction (EMI) for academic subject teaching in China, there is little research regarding the competencies that an EMI teacher needs for effective EMI course delivery and professional development (PD) in the higher education (HE) context. No research has investigated how those can be recognised through certain kinds of certification. This study fills the gap by investigating teachers' perspectives on competencies, certification and PD of EMI in relation to China through 133 survey returns and 12 semi-structured interviews. Our findings show that teachers have a generally positive attitude on EMI certification and PD programmes though few universities have made either a priority. Competencies required for effective EMI teaching include not only English proficiency and teaching skills through L2 but also skills of instruction in respective academic disciplines. This poses challenges for the design and implementation of EMI PD leading to teacher certification. The lack of official government involvement (at policy level) and institutional involvement (evaluation and faculty promotion) further complicates this issue in a top-down administrative-heavy country like China.
\end{abstract}

Keywords: EMI; medium of instruction; bilingual education; professional development; teacher certification; China 


\section{Introduction}

Universities around the world, in non-Anglophone countries, are increasingly introducing English as a medium of instruction (often referred to simply as English Medium Instruction, EMI) for academic subjects such as Engineering, Business Studies, and International Relations. This very rapid increase in EMI reflects the pre-eminence of English as the world's lingua franca whereby EMI becomes an essential vehicle for bringing about the internationalisation of Higher Education (HE) institutions, a goal which is reflected in a university's rankings (Hultgren 2014). China is certainly no exception to this growing global phenomenon (Hu 2009; Galloway et al. 2018). Tan (2012) noted that introducing English as an instructional medium in university teaching is a strategic choice to encourage the internationalisation of $\mathrm{HE}$ in China.

The switch from the first language as the medium of instruction (L1 MOI) to EMI however does not come without its tensions and challenges. The vast majority of these academic programmes are taught by content teachers whose first language is not English and, just as importantly, the majority of the students in their classes also do not have English as their L1. Consequently, it has been extensively documented that both teachers and students experience difficulty in teaching and learning content through English (see below) and a number of researchers and commentators have alluded to the need for a change in pedagogy in order to facilitate learning through EMI. However, little research has been carried out into how the pedagogy needs to change other than to state that it has to be more interactive (Klaassen and De Graaf 2001; Airey 2011) and there is to date no study which has specifically asked about the attributes or competencies that an EMI teacher needs to have in order to teach EMI effectively, how those competencies might be acquired, nor whether some kind of certification of those competencies is necessary. It was the purpose of this study to fill that gap in relation to EMI provision in China. This study is part of a larger study carried out 
at an international level exploring how much professional development (PD) EMI teachers had taken part in and the kinds of competencies that might be needed to teach EMI effectively.

\section{Literature review}

\section{EMI development in the world}

Although the extent and increase of EMI in Asia has not been measured in the systematic way that it has internationally in Europe (e.g. Wachter and Maiworm, 2008), we nevertheless have from a variety of national sources clear evidence of such an increase: in South Korea (Kim 2017); in Vietnam (Hamid, Nguyen, and Baldauf Jr. 2013); in Japan (Tsuneyoshi 2005); in Indonesia (Hamied and Lengkanawati 2018) and in China (Evans and Morrison 2011; Lei and Hu 2014; Jiang, Zhang, and May 2016). Moreover, it is clear that EMI programmes are being offered in Asia not only in order to facilitate home student mobility to HE in Anglophone countries (as has been the case historically) but also mobility within the Asian geographical area, this intra-continental mobility being stimulated by the creation of the Asia-Pacific Economic Cooperation (APEC) in the late 1980s and more recently a strong move to establish ever increasing economic cooperation through the ASEAN (The Association of South-East Asian Nations).

Research has responded to the increase in EMI, primarily through documenting the reactions and beliefs of teachers and students in individual countries. A review of such research (Author 1 et al.) has concluded that whilst both teachers and students see a longer term instrumental value in learning content through English (Hellekjaer 2010; Kang and Park 2005), in the short-term teachers have serious concerns about the effect it has on content learning and increased student anxiety (Cho 2012), on a range of pedagogical activities (Vinke 1995), and on enabling the use of humour in the classroom (Airey 2011). Students 
complain of limited listening skills (Cho 2012), and/or hesitancy to speak in English (Khan 2013). Moreover students often face not only a linguistic change but also a pedagogical change as they transit from L1MOI in secondary schools to EMI in tertiary (Sultana 2014).

Whilst recognising the importance of teachers having a high level of general English proficiency (Choi 2013), a number of commentators, as already noted above, have called for a change in pedagogy, particularly for more interactive and less teacher-centred HE classes. However, neither the level nor type of English proficiency needed to teach through EMI has been established, nor have the competencies a teacher needs to become more interactive and student-centred been researched. Moreover, whilst the argument could be made that in general (i.e. in L1 MOI) teachers in HE are not 'trained' to become such teachers (in the way that school teachers usually are) and few participate in extensive in-service PD, such preservice and/or in-service development is undoubtedly, and additionally, a pre-requisite for successful content teaching in an EMI HE context.

As well as a lack of consensus on what level and type of English proficiency teachers need and the competencies to teach effectively through EMI they should develop, there is no internationally recognised form of certification for those teacher competencies. Again, it could be argued that in HE very rarely does such a consensus for certification exist in L1 MOI. The counter argument however could be that, given the rapid development of EMI and increased mobility of students globally (moving from one EMI institution to another), then some sort of standardised certification would be extremely useful in order to address quality assurance issues.

In this study we define 'certification' as an official qualification given to an EMI teacher that documents evidence of the competence needed to teach their academic subject in a particular way. The research study which follows explores the possible components such certification might contain by drawing on previous research on EMI competencies for HE 
(Smit 2010; Kling and Stæhr 2012; Pilkinton-Pihko 2013). We define 'competencies' as the knowledge, understanding and skills needed to teach effectively and we propose that skills alone are not sufficient, but rather a deep understanding is needed of the challenges that EMI students with limited (but possibly varying) English proficiency and an emerging understanding of content are faced with on their EMI programmes. 'Professional development' in this study refers to a variety of specialised training and professional learning to help teachers to improve their knowledge, competence and skill for effective EMI teaching and career advancement.

\section{EMI development in China}

According to Galloway et al. (2018) EMI was first introduced in Shanghai by the municipal government to address the problem of expensive - and ineffective -Englishlanguage instruction in schools (see also Hu 2007). There has also been a drive for 'ChineseEnglish bilingual education' at the primary and secondary levels (Hu and McKay 2012) reflecting the link between secondary and tertiary education mentioned earlier.

132 out of 135 investigated higher education institutions (HEIs) in mainland China were offering EMI courses of some sort by 2006, averaging 44 courses per institution (Wu et al. 2010, cited in Lei and Hu 2014). It is important to maintain a perspective with regard to scale in China: in 2014, there were 25.48 million students studying in 2914 HEIs (National Bureau of Statistics of China). In addition to an increase in bilingual and EMI programmes, there has been an increase in joint programmes that award degrees from foreign universities, as well as the adoption of English textbooks for some disciplines (Lei and $\mathrm{Hu} 2014$ ). In the past decade, EMI in HE has evolved 'from being a Chinese-English bilingual teaching experience in well-developed socio-economic areas to being used right across the country' (Jiang, Zhang, and May 2016:1). 
As observed by $\mathrm{Hu}$, Li and Lei (2014), Mainland China is a relative latecomer to the introduction of EMI at tertiary level. In 2001, China's Ministry of Education (MoE) published a number of guidelines to encourage HEIs to actively start bilingual (shuang yu) teaching at undergraduate level in important and emerging disciplines, such as Information Technology, Biological Engineering, Finance and Law, and to use teaching materials and textbooks in its original language, usually English. The document set the goal that, in the leading universities, within three years, 5\%-10\% courses should be taught in English (Ministry of Education 2001).

The MoE launched an initiative to build 500 bilingual courses (shuang yu ke) as 'model courses' nationwide between 2007 and 2010, giving those selected relevant recognition and funding (Ministry of Education 2008). However, in practice, universities' encouragement of 'dual-language courses' remain at a verbal encouragement level only in the majority of universities we investigated. As in other parts of the world, in China a poor command of English by EMI teachers has been reported as limiting their interaction and their ability to improvise. Also, importantly as background to the current study, EMI demanded longer times for lesson preparation (Lei and $\mathrm{Hu} 2014$ ) and that many teachers lack the time and resources for this.

In summary, China is pursuing the same trajectory as many other non-Anglophone countries in introducing and developing EMI programmes. These programmes come with a number of important challenges not least of which are the competencies of teachers to adapt their pedagogy in order to ensure successful learning comparable to L1 MOI programmes as investigated in this paper. Moreover, we need to explore whether it is possible to provide certification recording evidence that those additional competencies have been achieved. Despite an increasing scholarly recognition of the importance of PD for faculty and an increase of PD in university practice (Wood et al. 2011; Jacob et al. 2018), no studies have 
systematically examined the certification and professional development of EMI teachers at China's higher education institutions. Against this backdrop, and in relation to specific challenges faced in the Chinese context, this study addressed the following research questions:

(1) What is the situation with regard to professional development and certification of EMI teachers in China's higher education context?

(2) What are EMI teachers' attitudes and beliefs regarding EMI certification and the key competencies required for effective EMI delivery?

(3) What might be the obstacles to EMI teacher certification and professional development in China?

\section{Method}

In order to attempt to answer these research questions this study adopted a mixed method design. Making reference to Crewell (2014), we collected, analysed and integrated both quantitative and qualitative data, in order to better address the research questions proposed. This study employed a quantitative survey supplemented by open-ended questions and triangulated via face to face interviews.

It first conducted an online survey targeted at EMI teachers working in the HE sector in China. In order to develop and refine this research instrument, we carried out pilot interviews with selected Chinese EMI teachers regarding their attitudes towards, and experiences in EMI teaching, training and certification. Based on their responses and extensive document research, we developed an initial draft survey. The draft survey, strategically designed in English, was then further piloted with Chinese EMI teachers. This round of piloting helped to refine the design and content of the survey. The targeted respondents were given a specific website address supported by a university learning platform in order to access the online survey. 
This final survey consisted of 25 closed questions and a number of fields where the respondents could freely comment or elaborate their answers. In the introduction to the survey, we presented potential respondents with examples of what EMI is and who qualified as an EMI teacher. We intentionally made it clear that we were not including teachers who taught English language as a content subject in English. However, a number of respondents stated that they were English teachers and therefore had to be excluded from this study. After data cleaning, there were 133 respondents who worked in China's HE as EMI teachers or were about to become EMI teachers. The numerical data was entered onto SPSS Version 25.

Among the 133 respondents, the vast majority taught at a state-owned university $(97.7 \%)$ while only 3 reported teaching at a private institution. The majority of the respondents were aged between 30-39 (54.9\%) and between 40-49 (34.6\%), followed by those aged 50 or above $(6.8 \%)$ and $20-29(3.8 \%)$. We asked the respondents to identify the subjects they taught, which were then categorised into six broad disciplines: Mathematical Sciences (21.1\%); Natural Sciences (21.1\%); Medical Sciences (6.0\%); Social Sciences (26.3\%); Humanities (9\%) and Humanities with a Language Focus (such as applied linguistics; translation studies) (25\%).

We also asked the respondents to clarify how long they have been teaching through English. Almost half of the respondents has been EMI teachers for less than five years (45.9\%). $21 \%$ of respondents stated that they were about to start teaching through English. But there were also more than 30\% who had taught in English for more than 5 years. 39.1\% respondents only taught undergraduate students and $11.6 \%$ only graduate students; the rest had experience with both kinds.

Based on an initial analysis of the survey, we conducted 12 semi-structured interviews with selected EMI teachers in China (see Table 1). Some of the interviewees were accessed by identifying those who expressed their willingness to participate in the interview in the 
survey. Some were accessed through snowball sampling, introduced by other interviewees. Some interviews were conducted face to face, some were conducted through Skype. The majority of the interviews were conducted in English, but the interviewees were given the option to switch to Chinese when they felt this was necessary. The overall structure of the interview mirrored the online survey in order to better corroborate the answers and fully address the research questions. Each interview lasted around 30 minutes. The interviews were then audited and transcribed in the original language in which they had been conducted; those using Chinese were further translated into English by one of the authors (a native Chinese). We also incorporated responses from the open-ended questions collected from the online survey thus forming a database for qualitative analysis.

\section{INSERT TABLE 1 ABOUT HERE}

By combining surveys and interviews, the research design allowed us to analyse EMI teachers' experiences, attitudes and beliefs regarding EMI competencies, certification and PD in-depth in the Chinese HE context.

\section{Findings}

This section presents the findings in three streams as structured by the research questions.

\section{Certification and PD of EMI teachers in China}

The first question concerned the current situation of PD and certification of EMI teachers in China's HEIs. Only 33.1\% EMI teachers investigated reported that they had been involved in any pre- or in-service training in EMI. 64.7\% respondents stated that their institutions did not have any sort of certification for taking part in EMI programmes while $18.8 \%$ answered that they didn't know. The interviews showed a similar situation with all respondents reporting that they did not know, or were not sure, of such certification. 
Interview data also suggested that, though most universities encouraged their teachers to teach through English because of a concern for internationalisation and international university rankings, it was rare for a university 'to publish a specific regulation specifying which course should be an EMI course' (interviewee G). For them, the routes to become EMI teachers varied considerably among institutions. No clear set of requirements or threshold of competencies were reported. As noted by interviewee A, 'in our department, it was left to some older professors to decide and approve whether you have the ability to teach through English.' In most cases, EMI teachers became such through a simple process of self-selection usually based either on personal interest or real-world necessity such as having one or more non-Chinese students in the class. Interviewee $\mathrm{C}$ painted a vivid picture:

It is totally my own choice. I started EMI teaching almost ten years ago because I had a student from Canada. Then he left, so I turned back to Chinese. A couple of years ago, we had students from Pakistan and France, so we turned to English again...This year I talked with my students to let them choose, they wanted to keep English...The university encourages teachers to give EMI courses, but there is no such policy in the real sense...but somehow we got interested in this ourselves.

The majority of interviewees stated that they would prefer to have a standardised way of selecting and being selected as EMI teachers, being backed up with incentives from the institution. For example, EMI courses should represent a higher number of teaching hours than L1 MOI courses. Interviewee A argued that this approach would make it more 'effective and efficient' in 'identifying the right person'.

The lack of a clearly stated requirement and selection mechanism in part contributed to the majority of EMI courses being in fact 'dual-language' courses or 'bilingual courses' (shuang yu ke), a term frequently deployed in the interviews. The term was used interchangeably with 'EMI' even though interviewees seemed to imply different teaching approaches. Interviewee E defined 'dual-language courses' as a form of teaching in which 
Chinese and English were used interchangeably- 'a mixed way of teaching'. Thus those courses designated as being instructed entirely through English were actually being instructed by varying combinations of English and Chinese with no apparent criteria for how much of each language might be used. Even this mixing of languages took various forms. For example, in one course, some lessons were taught in English and some taught in Chinese. In another, there was use of both languages in the same lesson or lecture. Another example might be that teaching materials (such as textbooks, notes or power point slides) might be in English while the spoken interaction might be almost entirely in Chinese. Or, reading assignments might be all in English while the classroom instruction was in Chinese.

The above complexity of EMI programme delivery led fairly seamlessly, in interviews, to EMI teachers' understanding of required competencies and attitudes on certification that we discuss in the next section. For some respondents it was why EMI professional development was highly valuable because 'it can give teacher a standard way to use and to get the basic EMI teaching skills, so they can perform well in a short time and increase efficiency' (interviewee B).

As shown in Table 2, an overwhelming number of respondents believed that the level of English proficiency and the skills used in teaching are different from those they used to communicate and interact at academic conferences where the working language is English. Similarly, $74.4 \%$ of respondents agreed that teaching had to change in the EMI context, compared to teaching through the L1. This was an important finding with which to contextualise our investigation of the competencies an EMI teacher might need in order to teach effectively.

INSERT TABLE 2 ABOUT HERE

However, only $33.1 \%$ EMI teachers investigated had been involved in any pre- or inservice training in EMI in order to acquire the necessary skills to adapt to such a change of 
roles, suggesting that the majority of EMI teachers have to develop their abilities based on individual experience and learning. This finding would suggest that it becomes even more important to understand teachers' understanding of the competencies required by an EMI teacher and their certification in the Chinese context.

\section{Teachers' attitudes regarding EMI certification and related competencies}

Table 3 shows the 133 respondents' reactions to the importance of a Certificate of Competence in EMI. In general, the majority of respondents believed that EMI certification was important on an individual, institutional and international level with only around 5\% believing that it was 'not at all important'. It may be useful to note that this finding may also have to do with the Chinese understanding of 'certification', which only serves as a threshold- those above the threshold can perform certain tasks (adequately), but such certification may not accurately reflect one's abilities (how good one really is). Recognition of the importance of an internationally comparable EMI certification is clear - as stated by interviewee A, an EMI certificate was certainly necessary if one wanted to spread EMI more broadly. The interview data also pointed to the potential use for students of certification; providing a kind of consensus as to the standard for teachers to become EMI teachers, one that is currently clearly unavailable. It would serve as a form of quality assurance and guaranteeing course quality for students.

\section{INSERT TABLE 3 ABOUT HERE}

The majority of interviewees believed that the university would benefit the most from having such certification. For one thing, it allowed the university to have a standard way of evaluating teachers' qualifications to become an EMI teacher. As stated by Interviewee D, it allowed the university to have a standard way to understand 'how to achieve your educational objectives based on planning, delivering and reviewing'. Furthermore, as claimed by 
interviewee $\mathrm{F}$, it ratcheted up the $\mathrm{HE}$ internationalisation and globalisation process, which had been quite high on their university's development agenda over the past decade.

It is noteworthy that interviewees did not think, in the current situation, that if certification became possible, they would benefit most from acquiring one, even though it might be intuitive to think so. For them a strong incentive to acquire certification would not exist unless it became part of the university's evaluation indicators or benefited their professional promotion. Interviewee $\mathrm{E}$ put it in the following way, and their view resonates with the current ambiguous status of EMI in China's HE sector.

\footnotetext{
In general, teachers don't really care whether we have a certificate or not, but whether we have the ability to perform certain tasks. Also, we need to consider who issues the certificate. If it is a pure language centre, I won't recognise the certificate. Why? There is no 'subject content'. I don't need all these things. I need to combine theories with practices. Whether a teacher can become an EMI teacher largely depends on his/her specialist knowledge and expertise - it cannot be judged purely by language.
}

Interviewees did demonstrate some divergence of attitudes according to disciplines, or 'subject content'. While interviewee G believed that it was not appropriate to have EMI courses in China in Science and Engineering disciplines, it was fine for subjects such as economics. Conversely interviewee $\mathrm{H}$ believed that it was easier to teach through English in Science and Engineering disciplines, but disciplines involving history, culture and politics could pose problems. These different views show that conceptualising and designing a certificate of competence to teach through EMI therefore first requires research to establish empirically based parameters to address such concerns, diverse views, and expectations.

The study further investigated from EMI teachers' perspectives, what might be the key competencies required for effective EMI delivery, and hence those that should be acknowledged by such a certification. This is closely related to the eventual design of future PD programmes for EMI teachers. 
Though a few respondents wrote 'I don't know' or 'not sure' when asked to freely express their opinions in the open-ended questions, the majority of respondents and interviewees agreed on a list of skills and competences required.

First and foremost was the language ability to teach through English. English proficiency was frequently brought up in the open-ended responses and interviews. Particular attention was paid to speaking since oral expression was key when it comes to classroom instruction. Informants also emphasised the ability of teachers to use English to explain difficult terminologies and academic concepts.

Second came general skills for pedagogy and communication as a teacher; and more importantly, teaching skills as an EMI teacher since one is using a second language not the L1. However, these skills were not articulated in any concrete way but framed as broad aims and aspirations. For example, one interviewee offered the following,

The teacher needs to be careful in the teaching because the students would face more challenges and may question the necessity to learn from L2 when they could choose L1. So teaching skills become very important to attract students.

Another respondent suggested that one had to be careful to ensure that through English the various genres of vocabulary and the interaction were sufficiently rich so as to avoid students 'falling asleep' (interviewee D). After having taken part in a two-week intensive EMI training course, interviewee $\mathrm{C}$ believed that he acquired better English proficiency and communication skills; but more importantly, he had started regarding 'teaching' as a subject of study and research. Such a realisation had allowed him to reflect on what is good teaching and what is bad - reflection that lies at the heart of EMI teaching in particular and all teaching in general.

The last core competency was EMI teachers' expertise in the respective disciplines and whether they were able to 'translate' such expertise in their teaching of academic 
subjects through L2. Some interviewees expressed their concern when using English as a medium to teach certain subject content. They believed that teaching methods and skills needed to be adjusted according to the different disciplines, for example different methods and skills between Physics and Philosophy. Therefore, EMI teaching and teachers' PD needed to be 'content-based' (interviewee K). Moreover interviewee I proposed that PD programmes, evaluation and certificates should reflect the subject differences in order to be more easily accepted and recognised. Hence, the design of PD programmes must take account of both English teaching and using English to teach a certain subject. As interviewee E recalled in reference to her participation in an EMI PD programme,

Our teaching needs to be aligned with different subjects and disciplines... so the training must be combined together - the EMI teaching methods, and the content in each subject...it is a pity that we didn't have the latter in the programme.

Therefore probing for future models of operation between language experts and subject teachers is needed in order to more 'effectively and efficiently deliver EMI courses' (interviewee L).

In general, those investigated with first-hand experience in EMI identified three key competencies required for effective EMI delivery: English proficiency, teaching skills through L2, and skills of instruction in respective academic disciplines. As our findings suggest, some of the competencies perceived by EMI teachers can be relatively easily measured and identified by a carefully designed certificate of competence, such as general language proficiency. Others are more complex, such as understanding the current linguistic knowledge of the students and adapting one's teaching accordingly. These complexities are further explored in the next section. 


\section{Obstacles towards EMI teacher competencies, certification and PD in China}

Based on analysis of our survey data and interview data, we were able to identify a number of problems in achieving the kinds of competencies referred to earlier (even by the respondents themselves) and therefore the design of PD programmes leading to certification.

In our survey, we probed EMI teachers' willingness to devote time and resources in order to achieve certain competencies leading to a potential certification. As shown in Table 4 , the response was not overly positive. Only $34.6 \%$ expressed a real interest in understanding 'how people learn English' in order to acquire a better grasp of their students' learning process when enrolled on an EMI course. Only $32.3 \%$ of respondents showed a strong interest in finding out about research into EMI and only $36.1 \%$ in actually reading journal articles on EMI themselves. We also asked about their willingness to demonstrate understanding of what they had read, and the result was quite similar - only $36.1 \%$ respondents chose 'very interested' and 'extremely interested'.

\section{INSERT TABLE 4 ABOUT HERE}

We also asked their opinion about being observed and about taking a combined test of academic and non-academic English leading to certification (see Table 5). With regard to a test the reaction was more positive with $66.9 \%$ respondents expressing willingness and $19.5 \%$ being unsure. However, $34.6 \%$ respondents indicated that they were not prepared to be observed in order to obtain certification. Among those who might be willing to be observed, there was no consensus on the format and procedure to do so, but most people indicated that it should be contained within a semester or less because 'we simply couldn't afford more time' (interviewee J). In order to comprehensively evaluate the teacher's ability in EMI teaching respondents indicated that such evaluation should be done by subject specialists with a good command of English (but they did not have to be native-English speakers), with a rich experience in teaching and particularly EMI teaching, and with expertise in the specific 
academic field. However, some interviewees expressed concern over the feasibility of assembling such a panel with experts that combine subject expertise with English proficiency - 'even if you can, there are so many disciplines, so you have to find different experts for different applicants' (interviewee D).

\section{INSERT TABLE 5 ABOUT HERE}

Students (whose first language was not English) were also mentioned as potential actors in evaluating EMI teachers' competencies because they, as recipients, would be able to assess directly whether they understood the EMI content teaching. As interviewee F articulated,

...how the students feel in many different ways - their areas of concentration, how well you can deliver effectively of those content in English, whether the way you teach actually help their understanding - it is not just lecturing or giving a talk, not just to your colleague - that's how I understand it.

According to our study, there was no consensus on what kind of status an EMI certification should have, or who should be the awarding body. For example, interviewee E believed that a certificate designed and implemented by international organisations could give it international status with transnational transferability. Her comment was echoed by interviewee $\mathrm{G}$, who argued for a non-profit non-governmental organisation, such as an organisation formed by bringing together EMI centres in a number of research universities. Collaboration between such a third-party organisation and an individual government could be an efficient way to design and implement such a certificate, according to interviewee $\mathrm{H}$.

Those who favoured a certificate with national status believed that the MoE in China should be the main issuing body. The greatest strength in this scenario was that a nationally recognised certification could be easily applicable and transferable to all HEIs within the country: 'It might be the only way to promote the certificate in an administrative-heavy 
country like China, which is quite different from western countries' (interviewee L); 'This is the only way to get teachers to be willing to be certified' (interviewee G). However, some questioned the validity of the government to play a part in the process; more importantly, the plausibility for the government to issue one, which may set barriers for potential teachers to engage in EMI teaching.

Even though few interviewees believed that the individual institution should be the one that provided the certificate, many informants emphasised its role in implementing a certificate and EMI teachers' PD programmes, and possible obstacles caused by institutional factors. For example, interviewee I further explained:

There is a lack of clear requirement and incentive, so we don't feel the need to engage in EMI teaching and get certified, .... for the moment, Chinese universities do not focus on teaching, but use publications and grants as the main indicators for promotion and professional development. So we don't have any incentive to improve teaching, let alone EMI teaching.

Similarly, several respondents in the survey's open-ended questions expressed the possible obstacles at the institutional level. For example, the university did not attach much importance to EMI certification and the already busy-schedule of teachers to participate in seemingly 'time-consuming' EMI PD programmes. Again, these factors are related to the official reorganisation and acceptability of such a certificate of competence.

Another possible obstacle frequently mentioned by respondents in the open-ended questions was the cost. The majority of interviewees believed that as the employer, the university should pay for the costs associated with EMI PD programmes and certification. This echoed the general view of the teachers that institutions are the ones that benefit the most from such certification. 


\section{Discussion and Conclusion}

EMI programmes in HE have been rapidly developing in the world and the Chinese context is no exception. The trend is likely to continue, despite a number of associated problems. This study sought to investigate China's situation with regard to the competencies, certification and PD of EMI teachers from their perspectives, informed by a nation-wide survey and semistructured interviews. The study investigated a number of broad competencies that EMI teachers might need and their attitudes on certification of those competencies to ensure effective teaching in China's HE context. In relation to specific challenges faced by Chinese EMI teachers, this study also paid particular attention to the possible obstacles related to EMI teacher PD and certification. By doing so, this study enriches the existing scholarly discussion on EMI development and fills the gap regarding key competencies an EMI teacher needs. It also provides evidence of the potential of establishing an internationally recognised certification.

We acknowledge a number of limitations. Considering the scale of education in China, the number of institutions that we were able to investigate was limited by the contact method and our available resources. The number of responses could have been potentially expanded if we had made the online survey open to everyone. But we strategically made the survey accessible to only those that had been given a specific website address to ensure the reliability of eligible respondents. Even so, the lack of control of respondents resulted in an elimination of a number of ineligible respondents during data cleaning. The method, however, allowed us to access a reasonable sample and to select the interviewees for further analysis.

Despite these limitations our findings suggest that although there was a generally positive recognition of the need for PD to develop a number of competencies for effective EMI delivery, and the necessity of subsequent certification, PD had not been a policy priority in most universities. Most 'EMI courses' in China exist as 'bilingual courses', offered by a 
mixed language of English and Chinese, with their teachers often becoming EMI teachers through self-selection. Such a situation inevitably affects the attitudes of EMI teachers on PD and certification. While the data suggest that teachers believe that both the institution and the individual can benefit from a certificate of competence, such a certificate not only needs to report on levels of General English proficiency and interactive skills to ensure successful delivery (comparable to L1 MOI programmes), but also to report such linguistic proficiency and skills in the respective disciplines and subjects (content-based teaching).

We thus fully acknowledge that the practicality of EMI teacher evaluation leading to certification is a noticeable challenge. Currently there seems to be no consensus on what kind of evaluation should be done, or by whom. However there seemed to be little appetite for a single institution or organisation in a far-off (probably Anglophone) country to provide certification.

Teachers in our sample were overall not particularly enthusiastic about gaining the understanding of how learners learn aspects of an L2, in reading EMI related research and demonstrating their understanding of it. Moreover at least one third was unwilling to be observed. This resonate with existing study on teachers' lack of time and resources for more effective EMI teaching (such as in Lei and $\mathrm{Hu} 2014$ ).

This situation is further complicated by the fact that subject content and subject genres play an important role and this role may be overlooked in an EMI context with insufficient resources to allow differentiation of PD content, which is often neglected in the current scholarly discussion. However, including evaluation of subject content delivery through EMI makes the already complicated procedure even more difficult. It also affects transferability of the certificate and the costs associated with it.

Programmes of PD therefore need to take into account a number of dimensions relating to competencies, as were identified in the study: the national context and their level 
of international transferability; the generic competencies and the subject specific competencies (see Figure 1). It is then possible that an individual who addresses all four of these dimensions would obtain the highest level of certification. The framework allows a more structured way of designing and implementing PD programmes for EMI teachers in particular and teachers in general at the higher education level. We of course only posit this framework as a possible way forward to be further explored by PD-based research.

\section{INSERT FIGURE 1 HERE}

In China, even though there is an ad hoc policy encouraging bilingual programmes, there are no detailed strategies or official regulations in this respect. The official rhetoric remains perhaps intentionally ambiguous over the inclusion of English in university teaching. At the institutional level, few universities currently directly link professional development of academics and subsequent promotion with EMI teaching, thus obtaining a certificate may be seen as an extra burden to those academics with an already busy schedule.

In this case, where there is a lack of official government participation, then serious doubts have to be raised regarding the acceptability of such EMI certification. How to establish its credibility and make universities nation-wide adopt certification and allocate the necessary resources for quality PD to take place become critical in an administration- and authority-heavy country such as China.

Administrative power may play an important force in promoting the design and implementation of a certificate of competence to EMI teachers. Even though a certificate might be designed and issued by an international agency (e.g. a consortium of top ranking universities around the world, as was suggested), such an agency would still have to take into account national considerations and find ways of cooperating with both the national government and individual university administrations. However the necessary momentum for promoting its implementation may only come if at a national level certification is seen as an 
instrument for raising the status of Chinese universities. Nonetheless, we do observe the national and institutional effort for greater level of internationalisation as reflected in China's recent 'Double First-Class' initiative and the noticeable increase of a number of Chinese universities in the Times Higher Education 2018 World University Ranking

Clearly, the research field is some way from being able to assert with conviction what a full set of competencies needed for an EMI teacher might be and how these might be delivered through PD and then certification. However, we believe we have made a start. The road ahead is not an easy one but we would venture that it should be embarked upon if generations of students are to fulfil their academic potential through EMI. The first step on that path, we believe, is further high-quality research focused specifically on implementation, and, particularly for the purposes of the readers of this article, in the rapidly expanding and changing EMI context in China.

\section{References}

Airey, J., 2011. Talking about teaching in English: Swedish university lecturers' experiences of changing teaching language. Iberica, 22, 35-54.

Cho, D. W., 2012. English-medium instruction in the university context of Korea: trade off between teaching outcomes and media-initiated university ranking. The Journal of Asia TEFL, 9(4), 135-163.

Choi, S. J., 2013. Issues and challenges in offering English-Medium Instruction: a close examination of the classroom experiences of professors. Studies in English Language \& Literature, 39(2), 275-306.

Creswell, J. W., 2014. Research design: Qualitative, quantitative, and mixed methods approaches (4th ed.). Thousand Oaks: SAGE Publications.

Galloway, N., Kriukow, J., and Numajiri, T., 2017. Internationalisation, higher education and the growing demand for English: an investigation into the English Medium of Instruction (EMI) movement in China and Japan. The British Council.

Evans, S. and B. Morrison., 2011. The student experience of English-Medium higher education in Hong Kong." Language and Education 25(2), 147-162.

Hamid, O., Nguyen, H., and Baldauf Jr. B., 2013. Medium of instruction in Asia: context, processes and outcomes. Current Issues in Language Planning, 14(1), 1-15.

Hamied, F.A. and Lenkanawati, N. S., 2018. Case study: EMI in Indonesia. In: R. Barnard and Z. Hasim, eds. English Medium Instruction programmes: perspectives from South-East Asian universities. London: Routledge, 55-69.

Hellekjaer, G.O., 2010. Language matters assessing lecture comprehension in Norwegian English-Medium Higher Education. In: C. DaltonPuffer, T. Nikula and U. Smit, eds. 
Language use in Content-And-Language-Integrated Learning (CLIL) classrooms. Amsterdam: John Benjamins, 233-258.

Hu, G., 2007. The juggernaut of Chinese-English bilingual education. In: A.W. Feng, ed. Bilingual education in China: practices, policies and concepts. Clevedon, UK: Multilingual Matters, 94-126.

$\mathrm{Hu}, \mathrm{G} ., 2009$. The craze for English-medium education in China: driving forces and looming consequences. English Today 25/4, 47. Available from http://doi. org/10.1017/S0266078409990472 [Accessed 21 May 2018]

Hu, G., Li, L., and Lei, J., 2014. English-medium instruction at a Chinese university: rhetoric and reality. Language Policy, 13(1), 21-40.

Hu, G. and McKay, S. L., 2012. English language education in East Asia: some recent developments. Journal of Multilingual and Multicultural Development, 33, 345-362.

Hultgren, A. K., 2014. English language use at the internationalised universities of Northern Europe: is there a correlation between Englishisation and world rank? Multilingua, 33(3-4), 389-411.

Jacob, J., Xiong, W., Ye, H., Wang, S., and Wang, X. 2018. Strategic best practices of flagship university professional development centers. Professional Development in Education, doi: 10.1080/19415257.2018.1543722.

Jiang, L., Zhang, L.J., and May, S., 2016. Implementing English medium instruction (EMI) in China: teachers' practices and perceptions, and students' learning motivation and needs. International Journal of Bilingual Education and Bilingualism. Doi: 10.1080/13670050.2016.1231166.

Kang, S. and Park, H., 2005. English as the medium of instruction in Korean engineering education. Korean Journal of Applied Linguistics 21(1), 155-174.

Khan, H. I., 2013. An investigation of two universities' postgraduate students and their teachers' perceptions of policy and practice of English medium of instruction (EMI) in Pakistani universities. Thesis (PhD). University of Glasgow.

Kim, E. G., 2017. English-medium instruction in Korean higher education: challenges and future directions. In: B. Fenton-Smith, P. Humphreys and I. Walkinshaw, eds. English medium instruction in higher education in Asia-Pacific: from policy to pedagogy. Dordrecht: Springer, $54-72$.

Klaassen, R.G., and De Graaff E. 2001. Facing innovation: preparing lecturers for Englishmedium instruction in a non-native context. European Journal of Engineering Education, 26(3), 281-289.

Kling, J. M., and Stæhr, L. S., 2012. The development of the Test of Oral English Proficiency for Academic Staff (TOEPAS). Technical report. Centre for Internationalisation and Parallel Language Use (CIP), ENGEROM, Faculty of Humanities, University of Copenhagen.

Lei, J., and Hu, G. W., 2014. Is English-medium instruction effective in improving Chinese undergraduate students' English competence? International Review of Applied Linguistics in Language Teaching, 52, 99-126.

Ministry of Education. 2001. Guanyu jiaqiang gaodeng xuexiao benke jiaoxue gongzuo tigao jiaoxue zhiliang de ruogan yijian [Guidelines for improving the quality of undergraduate teaching at higher education institutions]. Available from http://old.moe.gov.cn/publicfiles/business/htmlfiles/moe/moe_309/200412/4682.html [Accessed 7 June 2018].

Ministry of Education. 2008. Jiaoyubu caizhengbu guanyu pizhun 2008 niandu shuangyu jiaoxue shifan kecheng jianshe xiangmu de tongzhi [The Ministry of Education and the Ministry of Finance on building bilingual teaching model courses in 2008]. Available from 
http://www.moe.gov.cn/jyb_xxgk/gk_gbgg/moe_0/moe 1964/moe_2573/tnull 42446 .html [Accessed 7 June 2018].

National Bureau of Statistics of China. Available from http://data.stats.gov.cn [Accessed 7 June 2018].

Pilkinton-Pihko, D., 2013. English-Medium Instruction: seeking assessment criteria for spoken professional English. Thesis (PhD). University of Helsinki.

Smit, U., 2010. English as a Lingua Franca in higher education: A longitudinal study of classroom discourse. Berlin \& New York: De Gruyter Mouton.

Sultana, S., 2014. English as a Medium of Instruction in Bangladesh's higher education: empowering or disadvantaging Students? Asian EFL Journal, 16(1), 11-52.

Tan, D., 2012. Shuangyu jiaoxue: Zhongguo gaodeng jiaoyu guojihua de zhanlue xuanze [Bilingual education: strategy selection of internationalization of higher education in China]. Educational Research, 11, 83-86.

Tsuneyoshi. R., 2005). Internationalization strategies in Japan: the dilemmas and possibilities of study abroad programs using English. Journal of Research in International Education, 4(1), 65-96.

Vinke, A. A., 1995. English as the medium of instruction in Dutch Engineering education Thesis (PhD). Delft University of Technology.

Wächter, B., and Maiworm, F., 2014. English-taught programmes in European higher education: the state of play in 2014. Bonn: Lemmens Medien GmbH.

Wood, L.N., Vu, T., Bower, M., Brown, N., Skalicky, J., Donovan, D., Loch, B., Joshi, N., and Bloom, W., 2011. Professional development for teaching in higher education. International Journal of Mathematical Education in Science and Technology, 42 (7), 997-1009.

Wu, P., Wang, S. G., Jiang, X., Zeng, D. J., Guan, Y. X., and Li, X. F., 2010. Gaodeng xuexiao shuangyu jiaoxue de xianzhuang yanjiu he shijian tansuo [An exploratory study of English-medium instruction in Chinese higher education]. Beijing: Higher Education Press. 


\section{Tables}

Table 1. Interviewees in the study

\begin{tabular}{lccc}
\hline Code & Discipline & Years as EMI teachers & Overseas experience \\
\hline A & Biomedical engineering & More than 5 years & Study/research \\
B & Chemical engineering & About to start & Short-term study-visit \\
C & Automation & More than 5 years & Visiting scholar \\
D & Accounting & More than 5 years & Study/research \\
E & Education technology & More than 5 years & Visiting scholar \\
F & Software engineering & Less than 5 years & Study/research \\
G & Material engineering & Less than 5 years & Visiting scholar \\
H & Physics & About to start & Study/research \\
I & Computer Science & Less than 5 years & Study/research \\
J & Archaeology & About to start & Visiting scholar \\
K & Cultural studies & Less than 5 years & Study/research \\
L & History & More than 5 years & Visiting scholar \\
\hline
\end{tabular}

Table 2. Teachers' perception on EMI teaching

\begin{tabular}{lccc}
\hline & Yes/I agree & No/I disagree & I am not sure \\
\hline $\begin{array}{l}\text { Different proficiency } \\
\text { used in conferences }\end{array}$ & $84.2 \%$ & $2.3 \%$ & $13.5 \%$ \\
$\begin{array}{l}\text { and teaching } \\
\text { Teaching has to } \\
\text { change in EMI } \\
\text { context? }\end{array}$ & $74.4 \%$ & $9.8 \%$ & $15.8 \%$ \\
\hline
\end{tabular}

Table 3. Importance of Certification to EMI as perceived by EMI teachers in China

\begin{tabular}{lcccccc}
\hline & $\begin{array}{c}\text { Not at all } \\
\text { important }\end{array}$ & $\begin{array}{c}\text { Slightly } \\
\text { important }\end{array}$ & $\begin{array}{c}\text { Moderately } \\
\text { important }\end{array}$ & $\begin{array}{c}\text { Very } \\
\text { important }\end{array}$ & $\begin{array}{c}\text { Extremely } \\
\text { important }\end{array}$ & $\begin{array}{c}\text { Missing } \\
\text { data }\end{array}$ \\
\hline $\begin{array}{l}\text { How important } \\
\text { is certification } \\
\text { to you }\end{array}$ & $5.3 \%$ & $11.3 \%$ & $31.6 \%$ & $24.8 \%$ & $12.0 \%$ & $15.0 \%$ \\
$\begin{array}{l}\text { personally? } \\
\text { How important }\end{array}$ & $4.5 \%$ & $10.5 \%$ & $33.8 \%$ & $25.6 \%$ & $10.5 \%$ & $15.0 \%$ \\
$\begin{array}{l}\text { is certification } \\
\text { for your subject } \\
\text { department? }\end{array}$ & & & & & & \\
$\begin{array}{l}\text { How important } \\
\text { is certification } \\
\text { for your }\end{array}$ & $3.0 \%$ & $9.0 \%$ & $29.3 \%$ & $28.6 \%$ & $14.3 \%$ & $15.8 \%$ \\
institution? & & & & & & \\
$\begin{array}{l}\text { How important } \\
\text { is certification } \\
\text { globally }\end{array}$ & $4.5 \%$ & $5.3 \%$ & $31.6 \%$ & $28.6 \%$ & $15.0 \%$ & $15.0 \%$ \\
\hline
\end{tabular}


Table 4. Teachers' interest in activities related to EMI.

\begin{tabular}{|c|c|c|c|c|c|c|}
\hline Level of interest & $\begin{array}{l}\text { Not at all } \\
\text { interested }\end{array}$ & $\begin{array}{l}\text { Slightly } \\
\text { interested }\end{array}$ & $\begin{array}{l}\text { Moderately } \\
\text { interested }\end{array}$ & $\begin{array}{c}\text { Very } \\
\text { interested }\end{array}$ & $\begin{array}{l}\text { Extremely } \\
\text { interested }\end{array}$ & $\begin{array}{c}\text { Missi } \\
\text { ng }\end{array}$ \\
\hline $\begin{array}{l}\text { In how people learn } \\
\text { English }\end{array}$ & $6.0 \%$ & $18.8 \%$ & $25.6 \%$ & $27.8 \%$ & $6.8 \%$ & $15 \%$ \\
\hline In research into EMI & $6.8 \%$ & $16.5 \%$ & $29.3 \%$ & $20.3 \%$ & $12.0 \%$ & $15 \%$ \\
\hline $\begin{array}{l}\text { In reading selection } \\
\text { of journal articles on } \\
\text { EMI }\end{array}$ & $10.5 \%$ & $9.8 \%$ & $29.3 \%$ & $27.1 \%$ & $9.0 \%$ & $\begin{array}{c}14.3 \\
\%\end{array}$ \\
\hline $\begin{array}{l}\text { Demonstrating } \\
\text { understanding of } \\
\text { what you have read }\end{array}$ & $6.8 \%$ & $10.5 \%$ & $30.8 \%$ & $29.3 \%$ & $6.8 \%$ & $\begin{array}{c}15.8 \\
\%\end{array}$ \\
\hline
\end{tabular}

Table 5 Teachers' interest in taking English test and observed with certification as outcome

\begin{tabular}{lcccc}
\hline & No & Not sure & Yes & Missing \\
\hline $\begin{array}{l}\text { Willing to take test of academic and non- } \\
\text { academic English }\end{array}$ & $12.0 \%$ & $19.5 \%$ & $66.9 \%$ & $1.5 \%$ \\
Be prepared to be observed & $34.6 \%$ & $31.6 \%$ & $32.3 \%$ & $1.5 \%$ \\
\hline
\end{tabular}

\section{Figure}

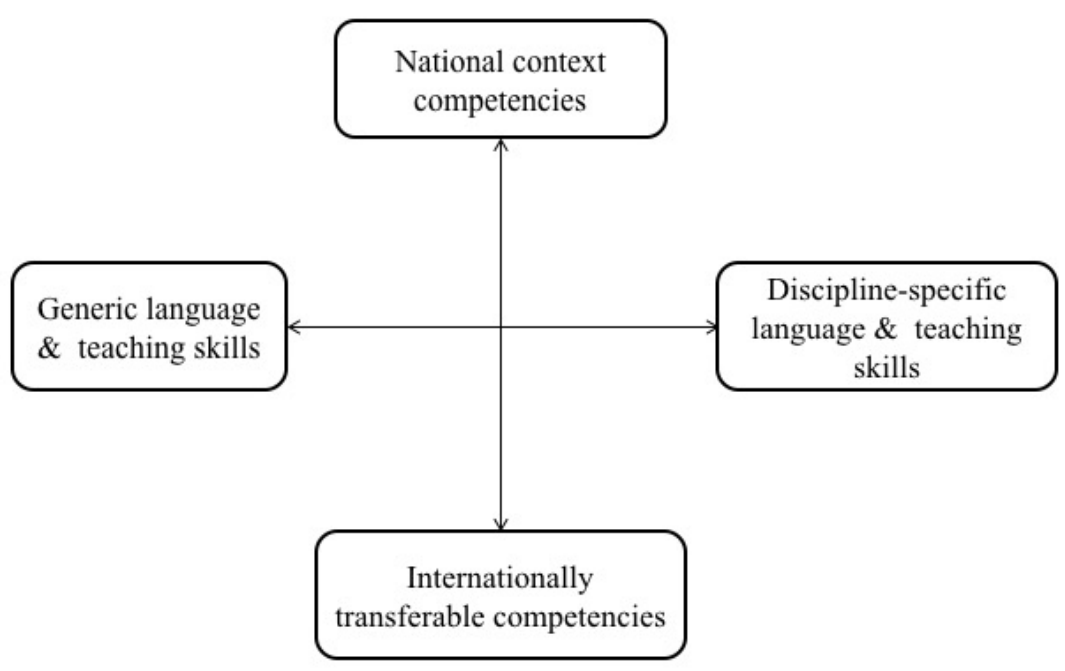

Figure $1 \mathrm{~A}$ theoretical framework of competencies of EMI teachers for professional development 